\title{
REVIEW
}

\section{The IPCC future projections: are they plausible?}

\author{
Vincent G ray* \\ Climate Consultant, 75 Silverstream Road, Crofton Downs, Wellington 6004, New Zealand
}

\begin{abstract}
IPCC (Intergovernmental Panel on Climate Change) future projections are based on a set of emission scenarios, IS92a to f, which are used to calculate future atmospheric concentrations of greenhouse gases. These, in turn, are used to calculate projections of radiative forcing, and then projections of future temperature and sea level change to the year 2100, using computer climate models. The assumptions of these 6 IPCC emission scenarios for the years 1995 and 2000 are compared with currently available information on greenhouse gas emissions, world population trends, and trends in world coal production. All of the scenarios exaggerate one or more of these quantities. Calculations of confidence limits on the net human-induced contribution of carbon dioxide to the atmosphere show a very high level of inaccuracy. When added to the even greater uncertainties connected with assumptions on the main greenhouse gas, water vapour, and also on clouds, plus the uncertainties of the computer models themselves, the current IPCC future projections of global temperature and sea level must be regarded as extremely unreliable. Fossil fuel emissions assumed by the IPCC scenarios for the year 2000 are plausible for scenarios IS92a, b, c and d, but not for e and f. The calculated rate of increase of atmospheric carbon dioxide concentration since 1990 assumed by the IPCC is exaggerated by $13 \%$ for all scenarios. The calculated rates of increase in atmospheric methane from 1990 to 2000 are exaggerated by 3 to 7 times, world population increases by up to $5.5 \%$, and world coal production increases by 60 to $510 \%$. The rate of increase of carbon dioxide in the atmosphere has been almost constant, at $0.4 \%$ a year, between 1971 and 1996, despite a 54\% increase in emissions from the combustion of fossil fuels over that period. Currently suggested reductions from present emission levels are therefore unlikely to influence carbon dioxide concentrations, or global temperatures. Since all of the IS92 scenarios exaggerate one or more current climate and economic trends, the calculated future projections of atmospheric greenhouse gas concentrations are thus correspondingly exaggerated. A more realistic set of scenarios, which would include a mechanism for continuous updating, needs to be developed, thus scaling down the current values. Even if this is done, however, the accumulated inaccuracies inherent in the final calculations of climatic effects are so great as to render them unreliable as a guide to public policy.
\end{abstract}

KEY WORDS: Climate change $\cdot$ Intergovernmental Panel on Climate Change $\cdot$ Emission scenarios

\section{THE IPCC EMISSION PROJECTIONS AND SCENARIOS}

Decisions by world governments on reductions in emissions of greenhouse gases are guided by the projections of possible future rises in global temperature and sea level provided by the Intergovernmental

\footnotetext{
*E-mail: vincegray@xtra.co.nz
}

Panel on Climate Change (IPCC). These projections are based on the IPCC emission scenarios IS92a to f, future projections of possible changes in greenhouse gas emissions, energy usage, economic progress and population change. From these scenarios projected future atmospheric concentrations of greenhouse gases can be calculated, and these can be used to calculate radiative forcing as an input to computer climate models giving future temperature and sea level changes to the year 2100 . 


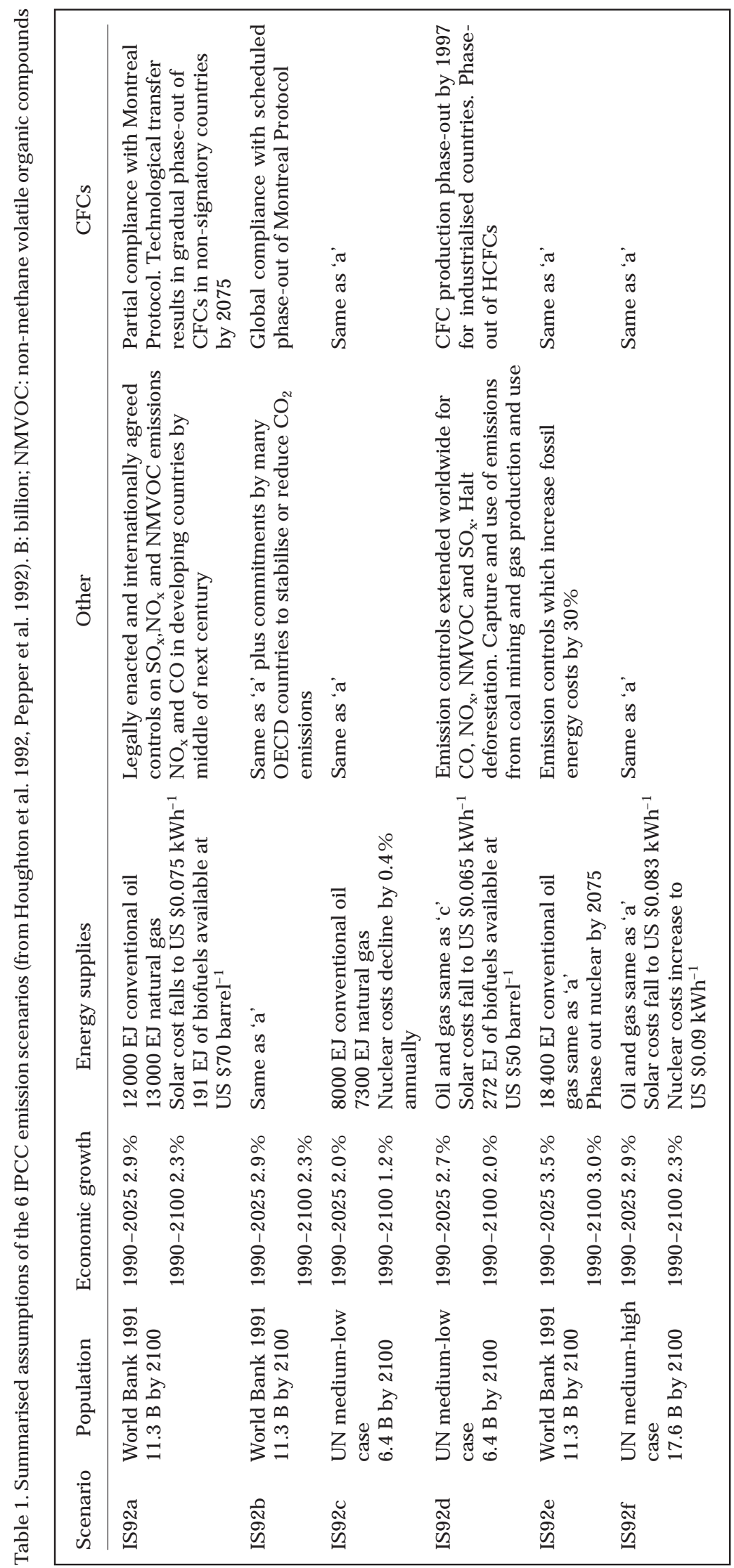

A set of emission scenarios (A, B, C and $D$ ) was presented in the first scientific assessment of the IPCC, Climate Change (Houghton et al. 1990). Four policy scenarios were developed by Working Group III of the IPCC, which postulated emissions of carbon dioxide $\left(\mathrm{CO}_{2}\right)$, methane $\left(\mathrm{CH}_{4}\right)$, nitrous oxide $\left(\mathrm{N}_{2} \mathrm{O}\right)$, chlorofluorocarbons (CFCs), carbon monoxide (CO) and nitrogen oxides $\left(\mathrm{NO}_{\mathrm{x}}\right)$ until the year 2100 . Estimates were also given of future changes in population, energy use, and economic progress. The scenarios were used to calculate the future changes in atmospheric concentration of several greenhouse gases (omitting the most important, water vapour), and from these the potential rise in global surface temperature, and in sea level, by the use of a range of climate sensitivity figures derived from computer models of the climate (High Estimate, Best Estimate, and Low Estimate climate sensitivity). Scenario A was referred to as 'Businessas-Usual', as it assumed that emissions would continue at their present rate, without any future attempt to control them. Most discussions of the consequences of continued emissions concentrated on this scenario, and some still do, despite the fact that the scenario itself is obsolete.

Climate Change 1992 (Houghton et al. 1992), the Supplementary Report to the IPCC Scientific Assessment, presented a new set of 6 emission scenarios (IS92a to f), which superseded the previous set. Table 1 summarises the assumptions made in these scenarios. Detailed documentation of the scenarios was provided in a supporting document (Pepper et al. 1992) which also gave tables of the assumptions, both regionally and globally, for key variables such as population, GNP, primary energy consumption and emissions. Climate Change 1992 is at pains to point out that 'none of the scenarios predicts the future'. The scenarios merely permit the evaluation of the consequences of a particular set of assumptions.

Climate Change 1994 (Houghton et al. 1995) was a further supplementary report of the original 1990 Climate Change, 
consisting of 2 parts, Radiative Forcing of Climate Change and An Evaluation of the IPCC IS92 Emission Scenarios. The latter section (Alcamo et al. 1995) was a limited study that broke down projections of energy-related $\mathrm{CO}_{2}$ emissions into 4 components: population growth, economic growth, energy intensity (the amount of primary energy used per unit of GDP), and carbon intensity (the amount of carbon emitted per unit of primary energy consumed). The assumptions of the 6 IPCC scenarios were compared with 87 other similar contemporary scenarios. It was pointed out that all the scenarios (apart from IS92b) are 'non-intervention' scenarios, based on an assumption that no further measures will be taken to control emissions beyond those agreed in 1990. Since emission controls are likely to increase above current arrangements, this assumption is unrealistic.

Scenario IS92b, the exception, was specifically devised to illustrate the effect of stated commitments for emission control that had been made, but not yet legally adopted by many OECD countries up to November 1991. In general, the components of the IS92 scenarios were found by Alcamo et al. (1995) to be fairly representative of other global scenarios, but not of regional scenarios.

The report made the statement: 'Scenarios deal with the future, so they cannot be compared with observations'. If they are to be useful, however, scenarios must surely have a relationship with reality. The authors did not seem to realise that the future has an unwelcome habit of becoming the present, and then the past. The IS92 scenarios all began in the year 1990. Since it is now 1997, we have over $6 \mathrm{yr}$ of climate measurements and economic data which can be used to check whether the scenarios are plausible.

\section{CARBON DIOXIDE}

\subsection{Carbon dioxide emissions from the combustion of fossil fuels}

The main human influence on possible future climate change is considered to be the emissions of carbon dioxide from the combustion of fossil fuels. The Framework Convention on Climate Change (FCCC) is concerned to modify the potential resulting climate change by international control on these emissions. Fig. 1 shows the latest figures of emissions of carbon dioxide from the combustion of fossil fuels, as published by the Carbon Dioxide Information and Analysis Center (CDIAC) (Marland et al. 1994, plus updates), with some additional recent figures for 1990 to 1996 from the World Energy Council (WEC) (Jefferson 1997). The total for the CDIAC figures includes cement production and gas flaring, but the WEC figures do not.

The total emission figures display a number of jumps, followed by periods of almost constant annual emissions. 1978 (5.076 Gt C) was almost the same as 1982 (5.070 Gt C). 1989 (6.068 Gt C) was almost the same as 1993 (6.057 Gt C). The 1994 CDIAC figure (6.200 Gt C) and the WEC figures for 1995 (6.340) and 1996 (6.513) show a recent increase.

The IS92 IPCC scenarios assume $6.0 \mathrm{Gt} C$ for 1990 as against $6.120 \mathrm{Gt} C$ as now measured by CDIAC and WEC. For the year 2000, IS92a assumes 7.0 Gt C, IS92b assumes $6.8 \mathrm{Gt} \mathrm{C}$, IS92C assumes $6.0 \mathrm{Gt} \mathrm{C}$, IS92d assumes $6.4 \mathrm{Gt} \mathrm{C}$, IS92e assumes 7.6 Gt C, and IS92f assumes $7.3 \mathrm{GtC}$. IS92a to d give plausible projections for fossil fuel combustion emissions for the year 2000, but IS92e and f do not.

\subsection{The carbon cycle}

Human-produced emissions of carbon dioxide and other greenhouse gases are thought to be responsible for the increase of concentration of these gases in the atmosphere, thus leading to a warming of the global climate. These emissions cause an aberration to the carbon cycle, the process whereby carbon dioxide is circulated between the atmosphere, the oceans, the land, and the biological species which occupy all of these. It is immediately obvious that all of the carbon dioxide emitted by combustion of fossil fuels does not end up in the atmosphere. The ratio between emis- 
sions and atmospheric addition is referred to as the 'airborne fraction'. The latest monthly figures of atmospheric carbon dioxide concentration, 1948 to 1996, from Tans \& Keeling (1997) are shown in Fig. 2. It will be seen that the rise in carbon dioxide concentration in the atmosphere was almost linear from 1971 to 1996,

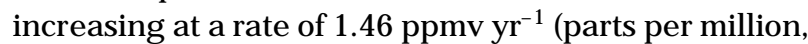
by volume, per year), or $0.4 \%$ of the 1996 figure.

The factor to be used to convert atmospheric carbon dioxide concentration in ppmv to total carbon in the atmosphere in Gt is 2.123 according to Enting et al. (1994). Therefore the increase of carbon in the atmosphere every year between 1971 and 1996 has, on average, been $1.46 \times 2.123=3.10 \mathrm{Gt} \mathrm{C} \mathrm{yr}^{-1}$. The emissions for 1971 were $4.23 \mathrm{Gt} \mathrm{C} \mathrm{(M} \mathrm{arland} \mathrm{et} \mathrm{al.} \mathrm{1994),} \mathrm{giving}$ an airborne fraction of 0.73 . The emissions for 1996 (J efferson 1997) were 6.51 Gt C, giving an airborne fraction of 0.48 . The airborne fraction from fossil fuel emissions has thus been steadily declining for the past $25 \mathrm{yr}$. It appears unlikely that cuts in emissions currently contemplated will have any effect on the current rate of rise of carbon dioxide in the atmosphere, which appears to be insensitive to total emissions.

If only a fraction of the fossil fuel combustion emissions ends up in the atmosphere, then the rest must be absorbed elsewhere. The nature and amount of this absorption have been something of a mystery. The 1990 IPCC Climate Change (Houghton et al. 1990), in its attempt to compile a carbon budget for humaninduced changes, ended up with a 'net imbalance' of $1.6 \pm 1.4 \mathrm{Gt} \mathrm{C} \mathrm{yr}^{-1}$ which could not be accounted for, referred to in the text as a 'missing sink'. Subsequent

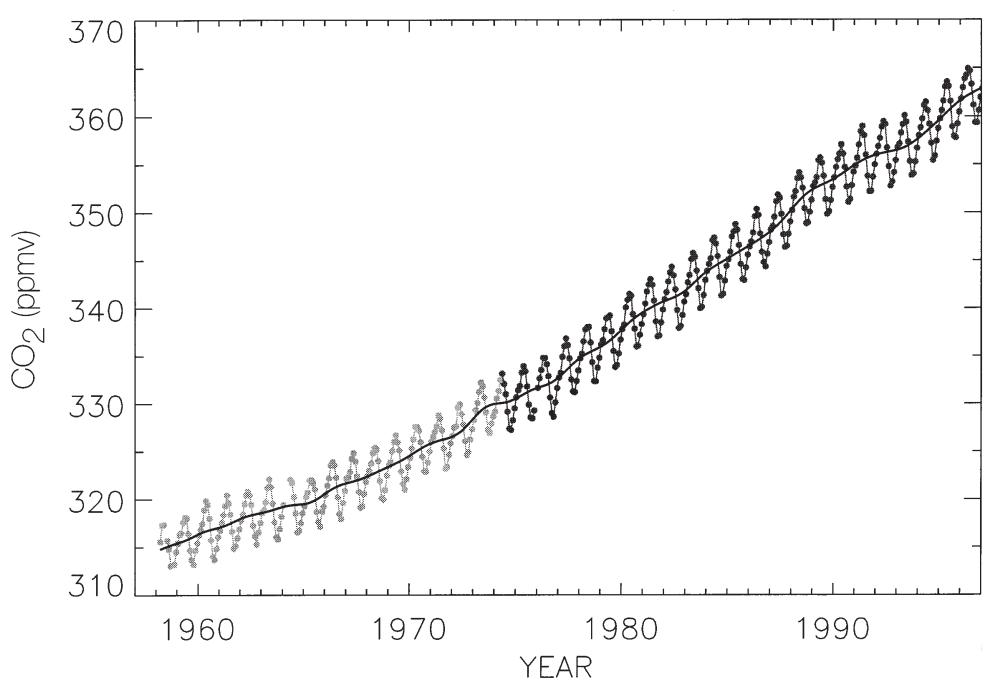

Fig. 2. Mean monthly atmospheric carbon dioxide concentrations at M auna Loa, HI. Data before 1974 are from Scripps Institution of Oceanography (SIO); data after 1974 are from the U.S. National Oceanic and Atmospheric Administration (NOAA). (Source: Tans \& Keeling 1997) studies have now identified the nature and quantitative effect of several of these absorbers of carbon dioxide as 'carbon dioxide fertilisation', 'nitrogen fertilisation' and 'miscellaneous climatic effects'. Since the carbon cycle, even before human intervention, consists of sources (emitters) and sinks (absorbers) of carbon dioxide, an attempt to evaluate human influence on this cycle must include human-induced changes of both emitters and absorbers. This principle is stated clearly in the supplementary paper to the recent IPCC Climate Change 1995 (Houghton et al. 1996), by Enting et al. (1994), as follows:

$$
\begin{aligned}
2.123 d C(t) / d t= & Q_{\text {foss }}(t)+D_{n}(t)-S_{\text {ocean }}(t) \\
& -S_{\text {fert }}(t)-S_{\text {resid }}(t)
\end{aligned}
$$

where $\mathrm{C}(\mathrm{t})$ is the atmospheric $\mathrm{CO}_{2}$ concentration (in ppmv) relative to dry air, $Q_{\text {foss }}(t)$ is the fossil fuel (plus cement) emission rate, $D_{n}(t)$ is the net carbon flux from land-use change, $\mathrm{S}_{\text {ocean }}(\mathrm{t})$ is the net carbon uptake by the ocean, $\mathrm{S}_{\text {fert }}(\mathrm{t})$ is the net flux associated with $\mathrm{CO}_{2^{-}}$ enhanced growth, and $S_{\text {resid }}(t)$ is a residual sink term.

Human-induced change in the carbon cycle is given by the total of the terms on the right hand side of this equation. Enting et al. have caused confusion by defining the term 'anthropogenic' as the sum of only the 2 first terms in this equation, the fossil fuel emissions and the net change in land use. This sum does not even represent the total emissions, since it contains an absorption term, regrowth, as an offset to 'deforestation' to give the net flux from land use changes. The net flux from land-use changes is further confused as the above equation clearly applies to global forests, whereas the elaborate calculations given in the IPCC Scenarios (Pepper et al. 1992) and the tables from which all the IPCC graphs have been compiled confine 'land-use change' to tropical forests only. A further 'sink' term of 'temperate forest regrowth' was identified subsequent to the publications of Pepper et al. (1992) and Enting et al. (1994), so it now appears in the IPCC human-induced perturbations in the carbon budget (Houghton et al. 1996) as a separate item, where 'anthropogenic' includes only net tropical land-use changes. Enting et al. (1994) clearly intended that their term 'anthropogenic' should include all land-use changes.

The list of human-induced perturbations to the carbon budget assumed by the IPCC as a basis for its scenarios as recently revised in Climate Change 1995 (Houghton et al. 1996) is given here as Table 2 . The figures represent the average yearly change, expressed in Gt C $\mathrm{yr}^{-1}$ over the period 1980 
to 1989 . This table selects an average over only $10 \mathrm{yr}$ (1980 to 1989), now $8 \mathrm{yr}$ out of date, without any attempt to determine trends over that period, such as the steady decline in the 'airborne fraction', which might be helpful in projecting into the future.

Previous studies on 'sensitivity' (Enting \& Lassey 1993, Enting et al. 1994, Houghton et al. 1996) confined their attention only to the so-called 'anthropogenic emissions' of Table 2. They did not include sensitivity effects from the other components of the carbon cycle.

Table 2, which claims to provide $90 \%$ confidence limits to each of the quoted contributions, can be used to give a complete estimate of the accuracy by which the net human contribution to aberrations in the carbon cycle is currently known, by amalgamating the inaccuracies associated with each of the items. Amalgamated confidence limits are arrived at by taking the square root of the sums of squares of the individual items.

Then, we have, for 1980 to 1989:

$$
\begin{aligned}
\text { Fossil fuel emission rate } & =\mathrm{Q}_{\text {foss }}(\mathrm{t}) \\
& =5.5 \pm 0.5 \mathrm{GtC} \mathrm{yr}^{-1}
\end{aligned}
$$

'Net changes in land use' must be obtained by subtracting 'Uptake by Northern Hemisphere forest regrowth' from 'N et emissions from changes in tropical land use':

$$
\begin{aligned}
\text { Net changes in land use } & =D_{n}(t)=1.6 \pm 1.0-0.5 \pm 0.5 \\
& =1.1 \pm 1.12{\mathrm{GtC} \mathrm{yr}^{-1}}
\end{aligned}
$$

This means that there is a greater than 1 in 10 chance that land use changes are a net sink. It should be noted that Southern Hemisphere temperate land use has not been included.

$$
\text { Ocean uptake }=\mathrm{S}_{\text {ocean }}(\mathrm{t})=2.0 \pm 0.8 \mathrm{Gt} \mathrm{C} \mathrm{yr}^{-1}
$$

The 'fertilisation' contribution now includes both 'carbon dioxide fertilisation' and 'nitrogen fertilisation'. These quantities are lumped together in Table 2 with 'climatic effects' to give a figure which balances the budget. The individual figures are given in the accompanying text. Carbon dioxide fertilisation is said to account for 0.5 to $2.0 \mathrm{Gt} \mathrm{C} \mathrm{yr}^{-1}$, so it is $1.25 \pm 0.75 \mathrm{Gt}$ $\mathrm{C} \mathrm{yr}^{-1}$. 'Nitrogen fertilisation' is given as 0.2 to $1.0 \mathrm{Gt} \mathrm{C}$

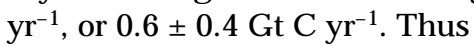

$$
\begin{aligned}
\text { Total fertilisation } & =\mathrm{S}_{\text {fert }}(\mathrm{t})=1.25 \pm 0.75+0.6 \pm 0.4 \\
& =1.85 \pm 0.85 \mathrm{Gt} \mathrm{C} \mathrm{yr}^{-1}
\end{aligned}
$$

'Climatic effects' are given in the text of Houghton et al. (1996) as, on average, zero, but with a variability of

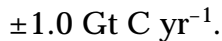

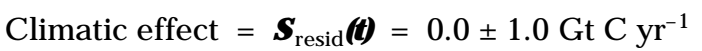

Assembling all these effects together, according to Eq. (1), we obtain

$$
\begin{aligned}
& 2.123 \mathrm{dC}(\mathrm{t}) / \mathrm{dt}=5.5 \pm 0.5+1.1 \pm 1.12-2.0 \pm 0.8 \\
& -1.85 \pm 0.85+0.0 \pm 1.0=2.75 \pm 1.97 \mathrm{Gt} \mathrm{C} \mathrm{yr}^{-1}
\end{aligned}
$$

This is compatible with the atmospheric increment of

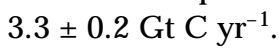

An alternative approach, as adopted above by the IPCC, is to lump together the $\mathrm{CO}_{2}$ fertilisation, nitrogen fertilisation, and climatic effect terms into one

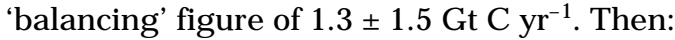

$$
\begin{aligned}
2.123 \mathrm{dC}(\mathrm{t}) / \mathrm{dt} & =5.5 \pm 0.5+1.1 \pm 1.12-2.0 \pm 0.8-1.3 \pm 1.5 \\
& =3.3 \pm 2.10 \mathrm{Gt} \mathrm{C} \mathrm{yr}^{-1}
\end{aligned}
$$

The extent of the inaccuracy should be noted. The $90 \%$ confidence limits are 72 or $64 \%$ of the net figure. It is more usual in statistical work to use the $95 \%$ confidence limits, which are approximately double the $90 \%$ figures. For the net human contribution to the atmosphere these are, then, 143 or $127 \%$.

The use of figures with this level of inaccuracy to calculate future concentrations of carbon dioxide means that the calculated projections are subject to similar levels of inaccuracy, and thus must be considered extremely unreliable. This applies not only to calculated future concentrations of carbon dioxide in the atmosphere, but also to the 'stabilisation scenarios'. Unknown future effects of technology and human

Table 2. Average annual budget of $\mathrm{CO}_{2}$ perturbations 1980 to 1989 in $\mathrm{Gt} \mathrm{C}$ yr ${ }^{-1}$ (Table 2.1 in Houghton et al. 1996). Error limits are estimated $90 \%$ confidence intervals

\section{$\mathrm{CO}_{2}$ sources}

(1) Emissions from fossil fuel combustion and cement production

(2) Net emissions from changes in tropical land use

(3) Total anthropogenic emissions $=(1)+(2)$

\section{Partitioning amongst reservoirs}
(4) Storage in the atmosphere
$3.3 \pm 0.2$
(5) Ocean uptake
$2.0 \pm 0.8$
(6) Uptake by Northern Hemisphere forest regrowth
$0.5 \pm 0.5$
(7) Other terrestrial sinks $=(3)-[(4)+(5)+(6)]\left(\mathrm{CO}_{2}\right.$ fertilisation, nitrogen fertilisation, climatic effects)
$1.3 \pm 1.5$ 
activity are likely to increase the uncertainties as the projections reach into the future. This applies particularly to the stabilisation scenarios, some of which extend to the year 2400, which are therefore highly speculative.

\subsection{A tmospheric carbon dioxide concentrations}

In order to calculate climatic effects, the emission figures of Pepper et al. (1992) have to be converted into projections of atmospheric concentrations, which are then used to calculate effects on the global heat balance using the computer climate models. It is shown above that the calculations for future concentrations of carbon dioxide are subject to a high level of unreliability. The actual figures finally assumed by the IPCC are nowhere published, so they have to be deduced from line drawings in Houghton et al. (1996) (Fig. 5b, p 23; Fig. 2.3, p 83). Measurements on these diagrams, supplemented by those from similar diagrams in draft IPCC documents, indicate that the IPCC is currently assuming that the rate of increase of carbon dioxide in the atmosphere for 1990 to 2000 was $1.65 \mathrm{ppmv} \mathrm{yr}^{-1}$, $13 \%$ higher than the 1971-1996 average.

The levels of inaccuracy involved mean that all the projections for carbon dioxide, and subsequent calculations based on them, are unreliable as guides to public policy.

\section{OTHER GREENHOUSE GASES}

\subsection{Water}

Pepper et al. (1992) do not mention the chief greenhouse gas, which is water vapour. There are no reliable past or present records of emissions of water vapour, and only a few recent measurements (Houghton et al. 1996, p 161) of the amount, or distribution, of water vapour in the atmosphere. It has to be dealt with entirely by theoretical speculation, mainly by modifications of the Clausius/Clapeyron equation (Houghton et al. 1996, Chapter 4). The whole subject is relegated to the status of a 'feedback', to be applied, as an oversimplified factor, to the final calculations of radiative forcing, instead of being included as a contributor to radiative forcing. Although the 'feedback' is usually considered to be positive, Lindzen (1990) argues that it is negative. Since not even average figures for water vapour concentration can be quoted, the uncertainty in the human contribution to water vapour change in the atmosphere must be very high-even higher than the large figures already established for the net carbon dioxide contribution.
Similar considerations apply to the other contributions of water to climate. Clouds are also dealt with as a 'feedback factor' in climate calculations, underlining the absence of observations and the large uncertainty of their presumed effect. Snow cover is another effect with similar uncertainty. In another example of inconsistency by the IPCC, cloud changes due to sulphate aerosols are not regarded as a feedback to radiative forcing, but their effects are taken to make a negative contribution to the radiative forcing itself. In general, climatic effects of forms of water add levels of uncertainty to calculations of temperature and sea level change which make them even more unreliable than the calculations from carbon dioxide.

\subsection{Methane}

Table 2.5a of Houghton et al. (1996) gives the 1990 atmospheric concentration of methane as $1700 \mathrm{ppbv}$ (parts per billion by volume). Scenarios IS92a and b assume 1749 in 1995 and 1810 in 2000. IS92c and d assume 1743 for 1995 and 1787 for 2000. IS92e assumes 1753 for 1995 and 1824 for 2000. IS92f assumes 1751 for 1995 and 1817 for 2000. Fig. 3 gives the most recent measured figures for globally averaged methane concentration from Dlugolencky (1997). It will be seen that the growth rate of methane in the atmosphere has been falling since 1983, and is currently approaching zero, to a stable atmospheric methane concentration of $1732 \mathrm{ppbv}$. The rate of increase for 1995 was about 2 ppbv yr-1. The 1990 concentration was 1700 ppbv (agreed by the IPCC), the 1995 figure was 1730 ppbv, the 1996 figure 1732 ppbv and the likely extrapolated year 2000 figure is the same, $1732 \mathrm{ppbv}$. The average rate of increase for 1990 to 1995 was 3 ppbv yr-1, and for 1995 to 20002 ppbv $\mathrm{yr}^{-1}$.

IPCC scenarios IS92a and $b$ assume 1749 ppbv for 1995 ( $1.1 \%$ too high) with a rate of increase, 1990 to 1995, of 4 times the measured rate. They assume 1810 ppbv for 2000 (4.5\% too high), a rate of increase, 1995 to 2000 , of $12.2 \mathrm{ppbv} \mathrm{yr}^{-1}, 6$ times the measured rate. Scenarios IS92c and d assume 1743 ppbv for 1995 (0.75\% too high), a rate of increase, 1990 to 1995 , of $8.6 \mathrm{ppbv} \mathrm{yr}^{-1}, 3$ times the measured rate, and $1787 \mathrm{ppbv}$ for 2000 (3\% too high), a rate of increase 1995 to 2000 , of $8.8 \mathrm{ppbv} \mathrm{yr}^{-1}, 4 \frac{1}{2}$ times too high. Scenario IS92e assumes 1753 ppbv for 1995 (1.3\% too high), a rate of increase, 1990 to 1995, of $10.6 \mathrm{ppbv} \mathrm{yr}^{-1}$, 3.5 times the measured rate, and 1824 ppbv for 2000 (5.3\% too high), a rate of increase, 1995 to 2000 of $14.2 \mathrm{ppbv} \mathrm{yr}^{-1}, 7$ times too high. Scenario IS92f assumes $1751 \mathrm{ppbv}$ for 1995 (1.2\% too high), a rate of increase, 1990 to 1995, of $10.2 \mathrm{ppbv} \mathrm{yr}^{-1}$, over 3 times 
the measured rate and $1817 \mathrm{ppbv}$ for 2000 (4.9\% too high), a rate of increase, 1995 to 2000, of $13.2 \mathrm{ppbv} \mathrm{yr}^{-1}$, over 6 times too high. IPCC scenarios thus ignore completely the established measured levels and trends of atmospheric methane concentration.

\subsection{Other greenhouse gases}

Pepper et al. (1992) estimate projected emission figures for carbon dioxide, methane, nitrous oxide, 14 halocarbons, carbon monoxide, higher nitrogen oxide $\left(\mathrm{NO}_{\mathrm{x}}\right)$, VOC (volatile organic compounds), and sulphur. As there are no reliable historic measured emission figures for these gases, there is no observational basis for checking the reliability of these calculations.

By contrast with carbon dioxide, detailed figures of calculated values for future concentrations of methane, $\mathrm{N}_{2} \mathrm{O}$, tropospheric ozone, and 14 halocarbons are tabulated in Houghton et al. (1996).

Houghton et al. (1996) indicate that atmospheric concentrations of nitrous oxide, carbon monoxide and several halocarbons are increasing at a lower rate than is assumed by calculations from the IPCC scenarios.

\section{OTHER TRENDS}

\subsection{World population trends}

The latest report of the United Nations Population Fund (UNFPA 1997) gives the average world population growth, 1995 to 2000 , as $1.4 \%$ per year. Taking their revised figure for 1995 (5687.1 million), and applying $1.4 \%$ a year, we get 6086.9 million as their estimate for 2000. IPCC scenarios IS92a, b and e assume 6205 million for $2000,1.9 \%$ too high, IS92c and d assume 6092 million, about right, and IS92f assumes 6420 million, 5.5\% too high.

\subsection{World coal production}

According to United Nations World Energy Statistics (1995), world coal production increased from 3.26 to $3.33 \mathrm{Gt} \mathrm{yr}^{-1}$ between 1990 and 1994 (2.1\%). Judging from the World Energy Council (J efferson 1997) emissions figures for solids (J efferson) shown in Fig. 1, the increase from 1990 to 1996 was $2.6 \%$, or an average, 1990 to 1996 , of $0.43 \%$ a year.

IS92a assumes an $18 \%$ increase for 1990 to 2000, an average rate 4.2 times 1990 to 1996 . IS92b assumes a $15 \%$ increase for 1990 to 2000 , an average rate 3.5 times 1990 to 1996. IS92C assumes a 7\% increase for 1990 to 2000, an average rate 1.6 times 1990 to 1996.

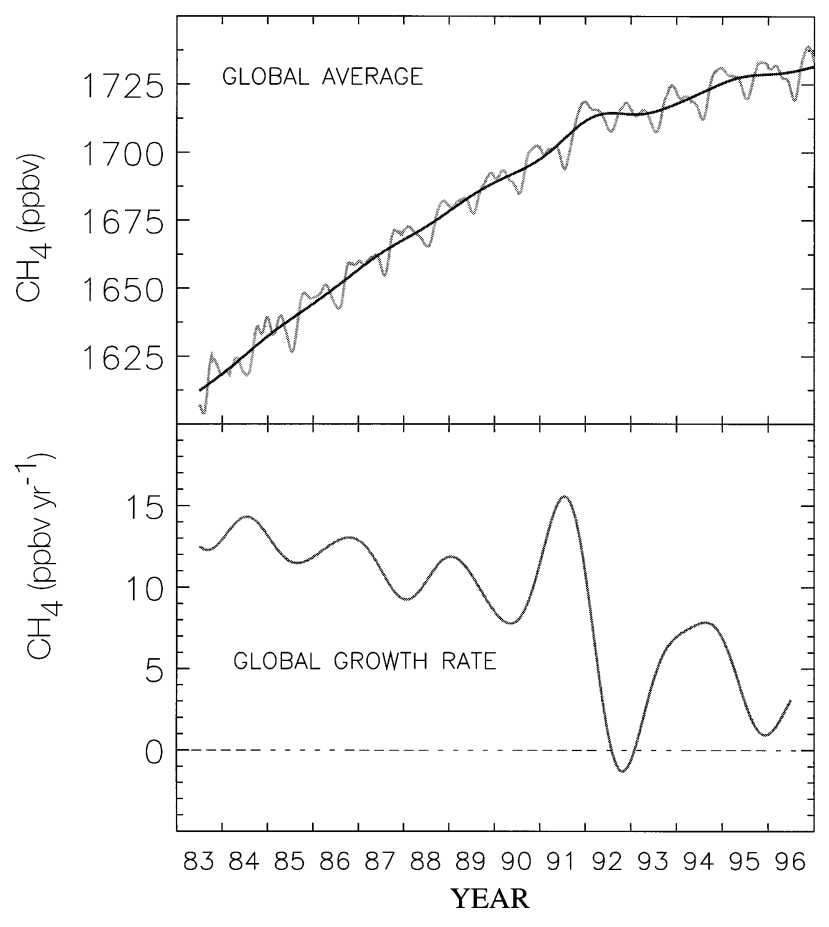

Fig. 3. Globally averaged atmospheric methane concentrations (the smoother line shows the long-term trend), and rates of increase, 1983 to 1996. From Dlugokencky (1997)

IS92d assumes a $16 \%$ increase for 1990 to 2000 , an average rate 3.8 times 1990 to 1996 . IS92e assumes a $25 \%$ increase for 1990 to 2000 , an average rate 6.1 times 1990 to 1996 . IS92f assumes a $21 \%$ increase for 1990 to 2000, an average rate 4.9 times 1990 to 1996 .

None of these assumed increases could possibly happen before the year 2000 .

\section{ASSE SSMENT}

\subsection{Status of the IPCC scenarios}

All of the IPCC scenarios exaggerate one or more of the climate and economic trends between 1990 and 2000. The current future projections by the IPCC (Houghton et al. 1995) for global temperature rise $(0.8$ to $4.5^{\circ} \mathrm{C}$ by 2100 ) and sea level rise ( 13 to $110 \mathrm{~cm}$ by 2100 ), based on these scenarios, are thus also exaggerated. Revised scenarios based on current trends would lead to a reduction in these estimates.

A new set of scenarios should include all greenhouse gases, including water vapour, should provide figures on all human-induced changes in the carbon cycle, and they should be made to correspond with current measured trends in atmospheric carbon dioxide, methane, and other greenhouse gases, and current 
trends in world population, energy supply, and economic development. There should be a continuous mechanism for monitoring the scenarios against future measurements, so that they can be updated realistically.

\subsection{Status of the IPCC projections}

IPCC projections depend initially on a calculation of the potential future changes in emissions of the various greenhouse gases. It is shown above that all of the IPCC scenarios exaggerate the extent of one or more of the factors determining future emissions. It is also shown that the inaccuracies involved in calculating future atmospheric concentrations of greenhouse gases, particularly the main ones, water vapour and carbon dioxide, are so great as to render the calculations highly unreliable. Finally, there are considerable uncertainties involved in the calculation of climate sensitivity from these calculations. The ratio between the 'High' and 'Low' estimates for climate sensitivity of the IPCC (Houghton et al. 1990, 1992, 1996) is a factor of 3. Part of this uncertainty is the poorly characterised influence of clouds. A combination of exaggeration and unreliability in the IPCC projections makes them unreliable as a guide to public policy.

\section{LITERATURE CITED}

Alcamo J, Bouwman A, Edmonds J, Grübler A, Morita T, Sugandhy A (1995) An evaluation of the IPCC IS92 emission scenarios. In: Houghton JT, M eira Filho LG, Bruce J, Lewe H, Callander BA, Haites E, Harris N, Maskell K (eds) Climate change 1994, Chap 6. Cambridge University Press, Cambridge, p 247-304

Dlugokencky E (1997) Website http://www.cmdl.noaa.gov/ $\mathrm{ccg} /$ figures/ch4trend_global.gif. National Oceanic and Atmospheric Administration (NOAA), NOAA/CMDL Carbon Cycle Group, Boulder, CO

Editorial responsibility: Chris de Freitas, Auckland, New Zealand
Enting IG, Lassey KR (1993) Projections of future $\mathrm{CO}_{2}$. CSIRO Division of Atmospheric Research Tech Pap No. 27, Melbourne

Enting IG, Wigley TML, Heimann M (1994) Future emissions and concentrations of carbon dioxide: key ocean/atmosphere/land analyses. CSIRO Division of Atmospheric Research Tech Pap No. 31, M elbourne

Houghton JT, Callander BA, Varney SK (1992) Climate change 1992: the supplementary report to the IPCC scientific assessment, Cambridge University Press, Cambridge

Houghton JT, Jenkins GJ, Ephraums JJ (1990) Climate change, the IPCC scientific assessment. Cambridge University Press, Cambridge

Houghton J T, M eira Filho LG, Bruce J, Lee H, Callander BA, Haites E, Harris N, M askell K (1995) Climate change 1994: Radiative forcing of climate change, and an evaluation of the IPCC IS92 emission scenarios. Cambridge University Press, Cambridge

Houghton J T, Meira Filho LG, Callander BA, Harris N, Kattenberg A, M askell K (1996) Climate change 1995: the science of climate change. Cambridge University Press, Cambridge

Jefferson M (1997) Carbon dioxide emissions 1990-1996. World Energy Council J , J uly 1997, p 3-10

Lindzen RS (1990) Some coolness concerning global warming. Bull Am M eteorol Soc 71:288-299

M arland G, Andres RJ , Boden TA (1994) Global, regional and national $\mathrm{CO}_{2}$ emissions. In: Boden TA, Kaiser DP, Sepanski RJ , Stoss FW (eds) Trends '93, a compendium of data on global change. Carbon Dioxide Information and Analysis Center, Oak Ridge National Laboratory, Oak Ridge, TN, p 505-584 (plus updates)

Pepper W, Leggett J , Swart R, Wasson J , Edmonds J , Mintzer I (1992) Emission scenarios for the IPCC: an update, supplementary document to Climate change 1992. Cambridge University Press, Cambridge

Tans P, Keeling CD (1997) Website http://www.cmdl.noaa. gov/ccg/figures/co2mm_mlo.gif. National Oceanic and Atmospheric Administration; NOAA/CM DL Carbon Cycle Group, Boulder, CO and Scripps Institute of Oceanography, La J olla, CA

UNFPA (United Nations Population Fund) (1997) The state of world population 1997: the right to choose. United Nations, New York

United Nations World Energy Statistics (1995) United Nations, New York

World Bank (1991) World development report 1991. Oxford University Press, New York

Submitted: October 8, 1997; Accepted: February 20, 1998 Proofs received from author(s): M ay 4, 1998 